
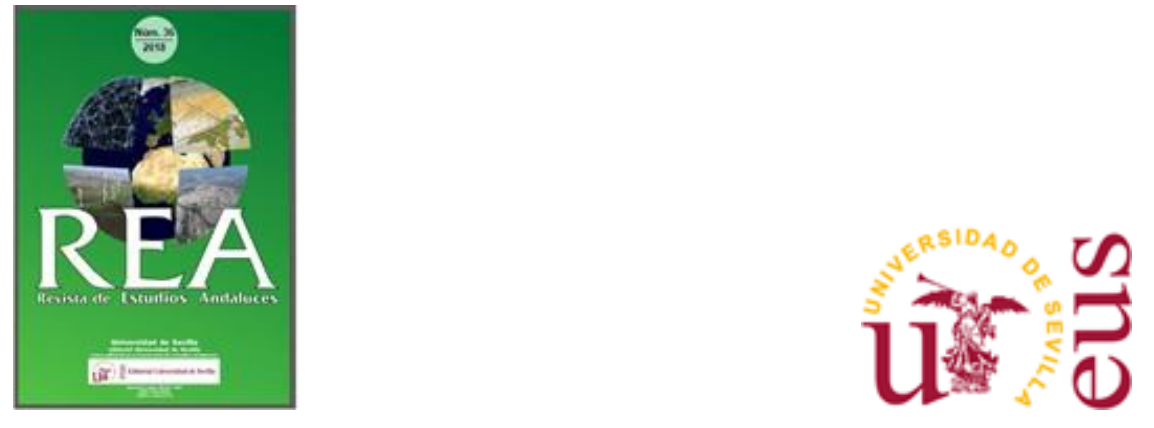

\title{
Revista de Estudios Andaluces (REA)
}

e-ISSN: $2340-2776$.

REA Núm. 36 (2018). http://dx.doi.org/10.12795/rea.2018.i36

\section{¿Armonización Universitaria en el Territorio Europeo? El Caso de Psicología y Biología}

\section{University Harmonization in the European Territory? The Case of Psychology and Biology}

\author{
Gustavo Eduardo Toledo-Lara \\ Universidad Isabel I \\ gustavo.toledo@ui1.es
}

Formato de cita / Citation: Toledo-Lara, Gustavo Eduardo (2018). ¿Armonización Universitaria en el Territorio Europeo? El Caso de Psicología y Biología. Revista de Estudios Andaluces, núm. 36, 98120.

http://dx.doi.org/10.12795/rea.2018.i36.05

Enlace artículo/to link to this article: http://dx.doi.org/10.12795/rea.2018.i36.05 


\title{
¿Armonización Universitaria en el Territorio Europeo? El Caso de Psicología y Biología
}

\section{University Harmonization in the European Territory? The Case of Psychology and Biology}

\author{
Gustavo Eduardo Toledo-Lara \\ Universidad Isabel I \\ gustavo.toledo@ui1.es
}

Recibido: 1 de marzo, 2018

Revisado: 27 de mayo, 2018

Aceptado: 6 de junio, 2018

\section{Resumen}

En este artículo se presenta un análisis del estado de la armonización universitaria en el Espacio Europeo de Educación Superior. Para tal fin y desde una perspectiva cualitativa, se examinaron las declaraciones de los ministros europeos encargados del sector universitario, los criterios orientadores del proceso de Bolonia y se estudiaron 55 universidades europeas, a partir del análisis de los grados de Psicología y de Biología para determinar cómo se configura la aplicación del proceso de Bolonia en ambos casos y comprobar, si en efecto, se ha producido la armonización universitaria en Europa, o si por el contrario, se han dado pasos aunque la armonización de los sistemas universitarios todavía sea una tarea pendiente.

Palabras clave: Universidad, educación superior, Espacio Europeo de Educación Superior.

\begin{abstract}
In this article one presents an analysis of the condition of the university harmonization in the European Space of Top Education. For such this purpose and from a qualitative perspective, there were examined the declarations of the European secretaries in charge of the university sector, the guiding criteria of the process of Bologna and studied 55 European universities, from the analysis of the degrees of Psychology and of Biology to determine how there is formed the application of the process of Bologna in both cases and to verify, if in effect, the university harmonization has taken place in Europe, or if on the contrary, they have given themselves steps though the harmonization of the university systems still is a hanging task.
\end{abstract}

Keywords: University, high education, European Higher Education Area.

Revista de Estudios Andaluces, núm. 36 (2018) pp. 98-120. e-ISSN: 2340-2776

http://dx.doi.org/10.12795/rea.2018.i36.05

(c) (i) $\Theta$

(c) Esta obra se distribuye con la licencia Creative Commons Reconocimiento-NoComercial-SinObraDerivada 4.0 Internacional (CC BY-NC-ND 4.0.) 


\section{INTRODUCCION}

Europa como región geográfica es el contexto en el que se desarrolla la reforma universitaria conocida como proceso de Bolonia. Este proceso ha sufrido modificaciones en cuanto a su implementación ya que, para adaptarse a toda una región, en este caso el continente europeo, debe contextualizarse de tal modo que la armonización de los procedimientos dentro del denominado Espacio Europeo de Educación Superior (en adelante, EEES) pueda llevarse a cabo.

Tanto el reconocimiento de créditos como la transferencia de estos constituyen una de las características definitorias de este proceso reformista a partir de la idea de que el estudiante es el centro de atención. Lógicamente tratar de que esto sea una realidad, implica una serie de acciones conjuntas a adoptar por parte de los sistemas nacionales de educación superior, los cuales deben avanzar en cuanto a la armonización y sincronización de dichos sistemas. El interés de un cambio en el desarrollo universitario en Europa, al parecer, ha encontrado en el proceso de Bolonia la posibilidad de cristalizarse, así y a juicio de De Garay, "sin lugar a dudas el Proceso de Bolonia ha sido uno de los principales motores para impulsar importantes reformas de la educación superior en Europa" (De Garay, 2012, 115). Por lo tanto, el espíritu reformista enfocado en la universidad y el reconocimiento del aspecto territorial se constituye en el contexto bajo el cual, el análisis de esta iniciativa adquiere relevancia al constituirse como empuje para la implementación de una política pública, dirigida al sector universitario cuyo punto de referencia está precisamente en la búsqueda de la armonización universitaria europea.

Una de las principales dificultades al momento de desarrollar la armonización universitaria europea, es el hecho de que la administración curricular no es uniforme en toda Europa, por ejemplo, no se otorga el mismo número de créditos ECTS en las titulaciones (en adelante ECTS = sistema de transferencia de crédito europeo), no se expresan los resultados de los estudiantes con la misma escala, ni todas las universidades de los países signatarios han adoptado el proceso de Bolonia como modelo a seguir. Esto trae como consecuencia que la buscada armonización de los sistemas universitarios todavía sea una tarea pendiente, a la vez que se hace necesaria mayor voluntad política de los estados para intentar asegurar un mejor desarrollo de esta reforma.

En síntesis, en este artículo se presenta un análisis del estado de la armonización universitaria en el territorio europeo, examinando las declaraciones de los ministros europeos encargados del sector universitario, los criterios orientadores del proceso de Bolonia y el resultado del estudio de 55 universidades europeas, a partir del análisis de los grados de Psicología y de Biología con el objeto de que se pueda conocer cómo se configura la aplicación del proceso de Bolonia en ambos casos y evidentemente el impacto de esta iniciativa para toda la región.

A efectos de esta investigación, se toman los grados de psicología y biología como muestra teórica con el fin de poder establecer un criterio comparativo desde estas titulaciones, para analizar cómo se lleva a cabo el proceso de Bolonia y, en definitiva, identificar aquellos elementos comunes y no comunes que permitan determinar hasta qué punto la armonización de los sistemas universitarios es una realidad o está en camino de serlo.

Revista de Estudios Andaluces, núm. 36 (2018) pp.98-120. e-ISSN: 2340-2776 http://dx.doi.org/10.12795/rea.2018.i36.05

(c) $($ ) $\odot$ (

(c) Esta obra se distribuye con la licencia Creative Commons Reconocimiento-NoComercial-SinObraDerivada 4.0 Internacional (CC BY-NC-ND 4.0.) 


\section{METODOLOGÍA}

Al reconocer el continente europeo como territorio que sirve de contexto para este análisis, se establecieron dos fases dentro del desarrollo de esta investigación: a) análisis de los criterios orientadores del proceso de Bolonia y b) análisis de los grados de Psicología y de Biología en un grupo de universidades de todos los países miembros.

En una primera fase, nos aproximamos al análisis documental el cual consistió en el análisis cualitativo de los documentos de los ministros europeos del área universitaria (declaraciones y comunicados de las reuniones de los ministros europeos del área universitaria producidos al final de cada reunión). Dichos documentos están enmarcados en el proceso de Bolonia y establecen una serie de aspectos y criterios ideológicos y procedimentales con miras a aplicar por parte de los países signatarios, las acciones conducentes a la armonización de la vida universitaria al Espacio Europeo de Educación Superior. En este sentido, como primer objetivo nos planteamos construir una matriz contentiva de los principios rectores del proceso de Bolonia, lo cual supone una lectura analítica de esos documentos.

De tal modo esta investigación se corresponde con la metodología cualitativa, pero sin la intención de obviar o rechazar los aspectos cuantitativos que son propios de aquellos estudios que pretenden obtener una cosmovisión lo más parecida a la realidad estudiada. Para la realización del análisis documental, se adoptó la propuesta de Salgado, A. (2007), quien expone una serie de categorías de análisis (cuadro 1) aplicadas al momento de analizar los documentos de los ministros europeos del área universitaria:

Cuadro 1. Categorías de análisis en Investigación cualitativa.

\begin{tabular}{|c|c|}
\hline Fase & Acciones \\
\hline Descubrimiento & $\begin{array}{l}\text { a. Buscar los temas emergentes. } \\
\text { b. Elaborar las tipologías. } \\
\text { c. Desarrollar conceptos y proposiciones teóricas. } \\
\text { d. Desarrollar una guía de la historia. }\end{array}$ \\
\hline Codificación & $\begin{array}{l}\text { a. Desarrollar categorías de codificación. } \\
\text { b. Codificar todos los datos. } \\
\text { c. Separar los datos pertenecientes a las diversas categorías de codificación. }\end{array}$ \\
\hline $\begin{array}{c}\text { Relativización } \\
\text { de los datos }\end{array}$ & $\begin{array}{l}\text { a. Datos solicitados o no solicitados. } \\
\text { b. Datos directos e indirectos. } \\
\text { c. Fuentes (Distinguir entre la perspectiva de una sola persona y las de un } \\
\text { grupo más amplio). } \\
\text { d. Los propios supuestos (autorreflexión crítica). }\end{array}$ \\
\hline
\end{tabular}

Fuente: Elaboración propia con datos tomados de: Salgado, A. (2007).

En síntesis, se procedió a seleccionar los documentos a analizar, posteriormente se realizó la lectura analítica de cada documento para identificar los criterios bajo los cuales se deben adscribir los países signatarios del proceso de Bolonia y por lo tanto establecer las categorías que permitieron extraer esos criterios. Todo lo anterior, desde una perspectiva europea ya que estos criterios orientadores son impulsados para toda Europa. 
En una segunda fase y como segundo objetivo, se planteó analizar la implementación actual de los criterios orientadores del proceso de Bolonia, para lo cual se han tomado como referencia los grados de psicología y de biología a modo de muestra teórica que sirva de punto de partida para el acercamiento a los datos y proporciones sobre su diseño y desarrollo. Cuando hablamos de implementación de los criterios de Bolonia en el $1^{\circ}$ y $2^{\circ}$ ciclo nos referimos a aquellos programas de grado o máster que están diseñados y administrados curricularmente bajo las orientaciones impulsadas en el EEES que conocemos como proceso de Bolonia y que, desde luego, cuentan con presencia de estudiantes matriculados.

Para este análisis fue necesario conocer la manera en que están diseñados los currículos de los grados antes señalados en 55 universidades pertenecientes a 47 países europeos (cuadro 2) En los casos en que en una misma Universidad no existan los grados de psicología y biología, se procedió a seleccionar una segunda Universidad (Suiza, República Checa, Irlanda, Portugal, Serbia, Suecia, Eslovenia y Reino Unido). Por otro lado, en aquellos países que no ofrecen ninguno de estos dos grados, se analizaron igualmente dos grados con el objeto de conocer el diseño curricular de los mismos, aunque estos no se correspondan con psicología o biología. (Ciencias de la educación y Enfermería en Andorra, Arquitectura y Administración de Empresas en Liechtenstein, Comunicación Social y Filosofía en el Estado Vaticano).

Los aspectos observados en cada Universidad fueron los siguientes: 1) escala de calificación utilizada, 2) grado de implantación de Bolonia en el $1^{\circ}$ y $2^{\circ}$ ciclo, 3) Rango de horas/curso académico, 4) Rango de horas/crédito establecido para la titulación, 5) $n^{\circ}$ de ECTS en los grados de Psicología y en Biología, y 6) Uso de los resultados de aprendizaje. Para la obtención de estos datos, se examinaron las fichas de los grados de cada titulación y de cada universidad anteriormente señalada. Por lo tanto, fue necesaria la lectura de 110 fichas. Estas denominadas "fichas" son aquellos documentos que contienen la información relativa al diseño curricular de las titulaciones, y es allí donde se identifican entre otros elementos, los aspectos señalados en párrafo anterior.

Es importante destacar que las estadísticas universitarias europeas se presentan oficialmente cada 2-3 años con lo cual, aquí se toma como fuente de esos datos el informe Eurydice del año 2015 siendo este informe, de momento, la última versión oficial publicada.

\section{EL CONTEXTO DE LA REFORMA UNIVERSITARIA EN EUROPA}

Hablar de reforma universitaria siempre supone un reto, ya que son muchas las aristas a considerar para efectivamente lograr una reforma en el sector universitario que responda fielmente a lo que la sociedad espera de ella. Hablamos entonces de necesidad de políticas públicas dirigidas al sector universitario, financiación, unificación de criterios para la administración curricular, acciones para la promoción del profesorado, atención al estudiante, expansión del sector universitario, internacionalización, entre otros.

Ahora bien, la reforma universitaria que se analiza en este trabajo definitivamente está vinculada con el término "armonización". Dicho término en el contexto universitario europeo significa que

Revista de Estudios Andaluces, núm. 36 (2018) pp.98-120. e-ISSN: 2340-2776 http://dx.doi.org/10.12795/rea.2018.i36.05

(c) (i) $\ominus$

cC. EY NG ND Esta obra se distribuye con la licencia Creative Commons Reconocimiento-NoComercial-SinObraDerivada 4.0 Internacional (CC BY-NC-ND 4.0.) 
Cuadro 2. Universidades analizadas por país $\left({ }^{*}\right)$

\begin{tabular}{|c|c|c|c|}
\hline País & Universidad & País & Universidad \\
\hline Andorra & U. de Andorra & Liechtesntein & U. Liechtenstein \\
\hline Albania & U. de Albania & Lituania & U. de Vilniaus \\
\hline Armenia & U. Khachatur & Luxemburgo & U. de Luxemburgo \\
\hline Austria & U. de Viena & Letonia & U. de Latvia \\
\hline Azerbaiyán & U. de Khazar & Moldavia & U. del Estado de Moldavia \\
\hline $\begin{array}{l}\text { Bosnia- } \\
\text { Herzagovina }\end{array}$ & U. de Sarajevo & Montenegro & U. de Montenegro \\
\hline Bélgica & U. de Lovaina & Macedonia & U. San Cirilo y Metodio de Skopje \\
\hline Bulgaria & U. de Sofía & Malta & U. d Malta \\
\hline Suiza & $\begin{array}{l}\text { U. de Ginebra } \\
\text { U. de Zurich }\end{array}$ & Países Bajos & U. de Amsterdam \\
\hline Chipre & U. de Chipre & Noruega & U. de Oslo \\
\hline República Checa & $\begin{array}{l}\text { U. Carlos de Praga } \\
\text { U. Masaryk }\end{array}$ & Polonia & U. de Varsovia \\
\hline Alemania & U. de Berlin & Portugal & $\begin{array}{l}\text { U. de Lisboa } \\
\text { U. de Oporto }\end{array}$ \\
\hline Dinamarca & U. de Copenhague & Rumanía & U. Babes-Bolyai \\
\hline Estonia & U. de Tartü & Serbia & $\begin{array}{l}\text { U. de Novi Sad } \\
\text { U. de Belgrado }\end{array}$ \\
\hline Grecia & $\begin{array}{l}\text { U. Aristóteles de } \\
\text { Tesalónica }\end{array}$ & Rusia & U. Estatal de Moscú \\
\hline España & U. Autónoma de Madrid & Suecia & $\begin{array}{l}\text { U. de Gotemburgo } \\
\text { U. de Uppsala }\end{array}$ \\
\hline Finlandia & U. de Helsinki & Eslovenia & $\begin{array}{l}\text { U. de Primorska } \\
\text { U. de Ljubljana }\end{array}$ \\
\hline Francia & U. La Sorbona & Eslovaquia & U. Comenius de Bratislava \\
\hline Georgia & U. de Tblisi & Turquía & U. Técnica de Oriente Medio \\
\hline Croacia & U. de Zagreb & Reino Unido & $\begin{array}{l}\text { U. de Oxford } \\
\text { U. de Cambridge }\end{array}$ \\
\hline Hungria & U. Budapense & Ucrania & U. Nacional de Karazin \\
\hline Irlanda & $\begin{array}{l}\text { U. Nacional de Irlanda } \\
\text { Maynooth University }\end{array}$ & Estado Vaticano & U. Pontifica de Santa Cruz \\
\hline Islandia & U. de Islandia & & \\
\hline Italia & U. di Roma & & \\
\hline Kazajistán & U. Nacional Al-Farabi & & \\
\hline
\end{tabular}

Fuente: Elaboración propia (2018)

$\left(^{*}\right)$ El orden de los países obedece al criterio utilizado en los documentos oficiales europeos, con lo cual, no se corresponde con el orden alfabético en idioma español.

todos los sistemas universitarios de los países signatarios deben aplicar en sus instituciones universitarias una serie de criterios comunes que aseguren la sincronización y unificación de procedimientos para asegurar la movilidad e intercambio de los actores que hacen vida en la Universidad. Todo esto, con el propósito de que la institución universitaria se convierta en un sujeto activo en el desarrollo de la economía europea y desde luego, en la generación de conocimiento. Alonso - Sáez, I., y Arandia - Loroño, M. (2017).

Autores como Morín, E. (2012) y Rabe, B. (2017) defienden una reforma universitaria en virtud de la constitución de una auténtica pertinencia social del sector universitario, sin embargo, dicha Revista de Estudios Andaluces, núm. 36 (2018) pp. 98-120. e-ISSN: 2340-2776

http://dx.doi.org/10.12795/rea.2018.i36.05

(c) (i) $\ominus$

Esta obra se distribuye con la licencia Creative Commons Reconocimiento-NoComercial-SinObraDerivada 4.0 Internacional (CC BY-NC-ND 4.0.) 
pertinencia no debería ser sinónimo de adecuación a las exigencias del desarrollo del mercado y de la industria, sino que la Universidad tiene la obligación de rendir cuentas a la sociedad ya que, en definitiva, la Universidad y la sociedad no son elementos antagónicos sino complementarios. Son complementarios en cuanto a que la Universidad no es algo ajeno al quehacer humano. En ella convergen diferentes puntos de vista, diferentes personas y diferentes modos de dar respuesta a los interrogantes que la sociedad exige. Por lo tanto, la Universidad y la sociedad no son cuerpos desvinculados.

La reforma universitaria se sitúa en un aspecto de primer orden al presentarse como una oportunidad para que la Universidad pueda repensarse, como producto de las heterogéneas transformaciones que experimenta la sociedad de cara a su búsqueda de adaptabilidad en el sistema social de relaciones. Garmendia, C. (2016). Por lo tanto, el proceso de reforma universitaria puede gestarse a partir del surgimiento de la sensación de agotamiento del modelo universitario existente. Sin embargo, mientras que el sector productivo europeo demanda talento humano calificado en función de sus prioridades, la Universidad en Europa necesita reafirmarse como casa de estudios que transmite valores y cultura, pero que además forma a los ciudadanos y fomenta la investigación. Se necesita entonces voluntad política para que la Universidad sin dejar de ser lo que es como institución, pueda adaptarse a los tiempos. En este sentido, parece que el proceso de la armonización universitaria europea también ha recibido ciertos influjos ideológicos de aquellas reformas de corte económico, impulsadas por el Banco Mundial, la Organización Mundial del Comercio y la Organización para la Cooperación y el Desarrollo. Verger, A. (2013).

Estas corrientes ideológicas si bien es cierto que han impactado en el sector universitario europeo, los países signatarios del EEES, no pueden asumir y llevar a la práctica de forma sincrónica los procesos de estandarización ya que como es de suponer, cada país tiene un contexto, una tradición y una manera de hacer políticas que, a su vez, pueden responder a la concertación de fuerzas ideológicas a lo interno de los países. Masjuan, J. M., y Troiano, H. (2018). Esto significa que cada país y cada universidad readapta las orientaciones y los criterios que se originan en los cuerpos decisorios a nivel internacional, a partir de sus intereses y posibilidades.

En este contexto, caracterizado por la presión económica a nivel global, el aumento de la presencia de las nuevas tecnologías, la búsqueda de la adecuación de un modelo universitario de cara a las exigencias de la futura sociedad del siglo XXI, y el sentido integracionista y europeísta de los diferentes sectores que hacen vida en Europa, fueron los elementos más destacables que condujeron a intentar constituir un sistema universitario que fuese capaz de congregar a los países bajo ciertos principios orientadores, con el objeto de construir paulatinamente un sistema universitario armonizado y estandarizado para todo el territorio europeo. Ferro, C., Martínez, A., y Otero, M. (2009).

Uno de los hechos que determinó las bases del consenso en torno a la concepción de la Universidad y el conocimiento, lo fue la denominada "Magna Charta Universitatum", proclamada en Bolonia en 1988. En dicha carta se establecieron una serie de principios rectores que buscaron la sincronía de las aspiraciones que, en materia de educación superior, perseguían las universidades signatarias.

Revista de Estudios Andaluces, núm. 36 (2018) pp.98-120. e-ISSN: 2340-2776 http://dx.doi.org/10.12795/rea.2018.i36.05

(c) (i) $\ominus$

c. Esta obra se distribuye con la licencia Creative Commons Reconocimiento-NoComercial-SinObraDerivada 4.0 Internacional (CC BY-NC-ND 4.0.) 
Esta acción de proclamar universalmente la importancia de la Universidad para la humanidad se convirtió en el punto de partida para lo que sería posteriormente, el conjunto de líneas de acción establecidas para homologar y estandarizar la educación superior socialmente pertinente. De tal modo, la "Magna Charta Universitatum", reflejó el espíritu de la concepción de universidad como aspecto de singular importancia en el desarrollo y equilibrio de la humanidad.

El carácter autonómico de la universidad declarado como primer punto de los principios generales de la Magna Charta Universitatum se ubica como raíz primigenia para lograr la pertinencia social de la Universidad de cara a la humanidad y a sus exigencias. Tünnermann Bernheim, C. (2008). El sentido declarativo de esta carta, no la exime de la intensión de querer sentar las bases en cuanto a la unificación continental de los principios definitorios hacia la educación superior. En dicha carta se establecieron una serie de principios rectores para los cuales los firmantes se comprometieron a "hacer todo lo posible para que los Estados, y los organismos supranacionales implicados se inspiren progresivamente en las disposiciones de esta Carta, expresión unánime de la voluntad autónoma de las universidades" (Magna Charta Universitatum, 1988, p. 3). La proclamación de la "Magna Charta Universitatum" requirió la ejecución de iniciativas que se desgranan de esta declaración.

Así, diez años después y enmarcado en la celebración de los ochocientos años de la Universidad de París, se reunieron académicos de toda Europa para debatir sobre lo que llamarían la "Europa del conocimiento", con miras a responder a la naturaleza global y a sus demandas ante la inminente llegada del siglo XXI. Como respuesta a estas demandas, Europa entendió que una reforma universitaria de alcance continental, era una acción imperativa precisamente para el impulso de una Universidad que avanzara conforme avanza la sociedad. De allí se concibe la idea de la figura del estudiante como centro de atención de la acción universitaria, y los criterios para que la universidad europea adopte la reorientación de sus titulaciones en función de su pertinencia social. San Martín, S., Jiménez, N., Sánchez - Beato, E. (2015). Garmendia, C. (2016).

El Espacio Europeo de Educación Superior (EEES) se inicia en 2010, siendo impulsado en la Conferencia de ministros europeos del área de educación superior celebrada en Budapest-Viena. Este espacio fue concebido con el objeto de que los sistemas de educación superior se armonizaran a partir de una serie de criterios comparables los cuales están presentes en todas las declaraciones ministeriales que se han producido a nivel europeo y que se detallan más adelante. Básicamente, esos criterios se organizan en 4 grandes áreas: 1.-estudiantil, 2.-administración y gobierno universitario, 3.-curriculum universitario, y 4.-personal docente.

Actualmente el EEES cuenta con 47 países signatarios. Lógicamente, el EEES encuentra en las instituciones de educación superior el espacio idóneo para llevar a la práctica los criterios orientadores acordados a nivel europeo y desde luego, los cuerpos decisorios a nivel nacional perfilan sus políticas de acción para tal fin. Sin embargo, es necesario apuntar lo que se entiende como institución de educación superior para toda la región europea. La universidad es una institución autónoma que, de manera crítica, produce y transmite la cultura por medio de la investigación y la enseñanza (Magna Charta Universitatum, 1988). 
En orden cronológico y hasta el presente, se han aprobado los siguientes documentos coincidiendo con los encuentros de ministros europeos encargados del área universitaria de los países miembros: Magna Charta Universitatum (1988), Declaración de La Sorbona (1998), Declaración de Bolonia (1999), Comunicado de la reunión de ministros europeos responsables de la enseñanza superior, Praga (2001), Comunicado de la reunión de ministros europeos responsables de la enseñanza superior, Berlín (2003), Comunicado de la reunión de ministros europeos responsables de la enseñanza superior, Bergen (2005), Comunicado de Londres (2007), Comunicado de la reunión de ministros europeos responsables de la enseñanza superior, Lovaina (2009) Declaración de Budapest y Viena sobre el Espacio Europeo de Educación Superior (2010), el Comunicado de Bucarest (2012), y la Declaración de Ereván (2015) (cuadro 3).

A modo de cierre de este punto, es importante destacar la idea de que la armonización de la universidad en Europa debe transitar por la adaptación de las ideas originadas a nivel europeo por parte de los países signatarios. Esto supone un compromiso entre los países decididos a adoptar criterios comunes en cuanto a la estandarización de sus procedimientos desde un punto de vista operativo y curricular. Esto último implica el reconocimiento de las enseñanzas universitarias en todo el territorio europeo. Garmendia, C. (2016). Comas, M., y de Bofarull, I. (2014).

Además de lo anterior, la readaptación de las orientaciones a nivel europeo por parte de los países firmantes del proceso de Bolonia no parece asegurar de forma inmediata, por ejemplo, la heterogeneidad en la duración de los estudios universitarios, Garmendia, C. (2016)., o la asignación de los ECTS a las titulaciones. Castillo, S. (2017). Entendiendo que un ECTS es aquel "medio para cuantificar el volumen de aprendizaje basado en la carga de trabajo que el estudiante necesita para alcanzar los resultados esperados de un proceso de aprendizaje en un nivel concreto" ECTS User's guide. $(2011,36)$. Con lo cual, la armonización universitaria europea no ha dejado de ser un reto, si bien, ha estado presente al menos como intencionalidad y es de reconocer, además, los avances operativos logrados en cuanto a esta intención, aunque quede mucho por lograr. García-Berro, E., Dapia, F., Amblàs, G., Bugeda, G., y Roca, S. (2009).

\section{RESULTADOS Y DISCUSIÓN}

Para iniciar el análisis de la información sobre lo que ocurre con los grados de psicología y biología en cuanto a la armonización universitaria en el territorio europeo, resulta necesario señalar los criterios orientadores bajo los cuales se organiza la actividad universitaria en Europa. Una vez analizadas las 10 declaraciones de los ministros y encargados europeos del sector universitario, celebradas entre 1988 y 2015, se procedió a identificar aquellos criterios establecidos para todo el territorio europeo en materia universitaria. A efectos de esta investigación, los criterios fueron agrupados en 4 grandes áreas de acción: 1) estudiantil, 2) administración y gobierno universitario, 3) curriculum universitario y 4) personal docente. (cuadro 4).

Revista de Estudios Andaluces, núm. 36 (2018) pp.98-120. e-ISSN: 2340-2776 http://dx.doi.org/10.12795/rea.2018.i36.05

(c) (†) $\ominus$

(c) Esta obra se distribuye con la licencia Creative Commons Reconocimiento-NoComercial-SinObraDerivada 4.0 Internacional (CC BY-NC-ND 4.0.) 
Cuadro 3. Sinopsis de las declaraciones de encargados de educación superior en Europa respecto al Proceso de Bolonia.

\begin{tabular}{|c|c|c|}
\hline Documento & Principales ideas & Signatarios \\
\hline $\begin{array}{c}\text { Magna Charta } \\
\text { Universitatum } \\
1988\end{array}$ & $\begin{array}{l}\text { Libertad de investigación y enseñanza, medios adecuados } \\
\text { para su realización. Selección de profesores y su estatuto. } \\
\text { Indisociabilidad en la actividad investigadora y docente. } \\
\text { Garantizar a estudiantes la salvaguarda de sus libertades. } \\
\text { Intercambio de información, documentación e iniciativas } \\
\text { comunes para progreso de conocimientos. Política general } \\
\text { de equivalencia. }\end{array}$ & $\begin{array}{l}\text { Presidente de la } \\
\text { Conferencia de rectores } \\
\text { europeos. Rectores de: } \\
\text { Bolonia, París I, Lovaina, } \\
\text { Ultrech y Barcelona. } \\
\text { Presidente subcomisión } \\
\text { para la universidad del } \\
\text { Consejo de Europa. }\end{array}$ \\
\hline $\begin{array}{l}\text { La Sorbona } \\
25 / 08 / 1998\end{array}$ & $\begin{array}{l}\text { Impulso del ETCS. Convalidación de créditos obtenidos. } \\
\text { Movilidad estudiantil y profesoral. Facilitar acceso a } \\
\text { programas, multidisciplinariedad, idiomas y uso de las TIC. } \\
\text { Reconocer internacionalmente la titulación del } 1^{\circ} \text { ciclo } \\
\text { como nivel cualificado. Máster de corta duración y } \\
\text { doctorado más extenso. }\end{array}$ & $\begin{array}{l}\text { Ministros de educación } \\
\text { de: Alemania, Francia, } \\
\text { Italia y Reino Unido. }\end{array}$ \\
\hline $\begin{array}{l}\text { Bolonia } \\
19 / 06 / 1999\end{array}$ & $\begin{array}{l}\text { Competitividad del sistema europeo de educación superior } \\
\text { a nivel mundial. Políticas públicas necesarias para lograr los } \\
\text { objetivos. Desarrollo curricular. Sistema de titulaciones } \\
\text { comprensible y comparable. Suplemento del diploma. } \\
\text { Sistema de } 2 \text { ciclos: diplomatura y licenciatura. Acceso a } 2^{\circ} \\
\text { ciclo con estudios de } 1^{\circ} \text { ciclo de } 3 \text { años mínimo. } 2^{\circ} \text { ciclo } \\
\text { conduce al grado de maestría y/o doctorado. Cooperación } \\
\text { interinstitucional, movilidad, integración de formación e } \\
\text { investigación. }\end{array}$ & 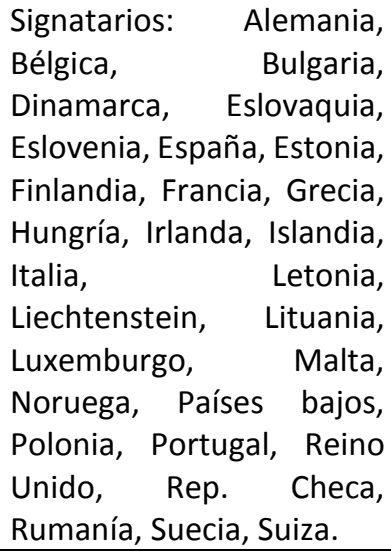 \\
\hline $\begin{array}{c}\text { Praga } \\
19 / 05 / 2001\end{array}$ & $\begin{array}{l}\text { Sistema de titulaciones reconocible y comparable. Sistema } \\
\text { basado en dos ciclos. Sistema de créditos común para todos } \\
\text { los estados miembros. Promover el atractivo del EEES. } \\
\text { Promoción de igualdad y de cooperación europea en el } \\
\text { aseguramiento de la calidad. Aprendizaje a lo largo de la } \\
\text { vida. }\end{array}$ & $\begin{array}{l}\text { Se agrega: Chipre, Croacia } \\
\text { y Turquía. }\end{array}$ \\
\hline $\begin{array}{c}\text { Berlín } \\
\text { 19/09/2003 }\end{array}$ & $\begin{array}{l}\text { Acreditación de la calidad. Promoción de la movilidad. } \\
\text { Progresar en el sistema de créditos. } \\
\text { Acercamiento de la investigación tecnológica, social y } \\
\text { cultural a las necesidades sociales. Red de trabajo a nivel } \\
\text { doctoral. Nivel doctoral como } 3^{\circ} \text { ciclo en el Proceso de } \\
\text { Bolonia. }\end{array}$ & $\begin{array}{lr}\text { Se agrega: } & \text { Albania, } \\
\text { Andorra, } & \text { Bosnia- } \\
\text { Herzegovina, } & \text { Estado } \\
\text { Vaticano, } & \text { Macedonia, } \\
\text { Rusia y Serbia. }\end{array}$ \\
\hline $\begin{array}{l}\text { Bergen } 19 \text { y } \\
20 / 05 / 2005\end{array}$ & $\begin{array}{l}\text { El EEES se estructura en tres ciclos. Planes nacionales para } \\
\text { mejorar la calidad. Reconocimiento de aprendizajes } \\
\text { previos. Autonomía necesaria para las reformas acordadas. } \\
\text { Financiamiento sostenible. Sinergia educación superior y } \\
\text { otros sectores. Interdisciplinariedad en doctorado. }\end{array}$ & $\begin{array}{l}\text { Se agrega: Armenia, } \\
\text { Azerbaiyán, Georgia, } \\
\text { Moldavia y Ucrania. }\end{array}$ \\
\hline $\begin{array}{c}\text { Londres } \\
18 / 05 / 2007\end{array}$ & $\begin{array}{l}\text { Compatibilidad y comparabilidad de los sistemas de } \\
\text { educación superior. Eliminar barreras al acceso y a la } \\
\text { progresión entre ciclos. Implementación adecuada del } \\
\text { ETCS. Reforzar reglamentación del } 3^{\circ} \text { ciclo. Integrar } \\
\text { doctorado en políticas institucionales. Prioridades: }\end{array}$ & Se agrega: Montenegro. \\
\hline
\end{tabular}

Revista de Estudios Andaluces, núm. 36 (2018) pp. 98-120. e-ISSN: 2340-2776

http://dx.doi.org/10.12795/rea.2018.i36.05 


\begin{tabular}{|c|c|c|}
\hline & $\begin{array}{l}\text { movilidad, dimensión social, empleabilidad, EEES en } \\
\text { contexto global. }\end{array}$ & \\
\hline $\begin{array}{l}\text { Lovaina } 28 \text { y } \\
29 / 04 / 2009\end{array}$ & $\begin{array}{l}\text { Garantizar que universidades cuenten con recursos } \\
\text { necesarios. Programas de doctorado de alta calidad. } \\
\text { Mejorar el entorno de aprendizaje. Calidad de oferta y } \\
\text { transparencia de la información. Apoyo al aprendizaje a lo } \\
\text { largo de la vida. }\end{array}$ & \\
\hline $\begin{array}{l}\text { Budapest y } \\
\text { Viena } 11 \text { y } \\
12 / 03 / 2010\end{array}$ & $\begin{array}{l}\text { Mejorar movilidad estudiantil y profesional, la enseñanza - } \\
\text { aprendizaje y la empleabilidad. Libertad académica, } \\
\text { autonomía y rendición de cuentas como principios del } \\
\text { EEES. Aseguramiento de recursos necesarios. Medidas para } \\
\text { la adecuada aplicación de los principios de Bolonia. } \\
\text { Aprendizaje sobre medio ambiente. Fomento del } \\
\text { aprendizaje centrado en el estudiante. }\end{array}$ & Se agrega: Kazajistán. \\
\hline $\begin{array}{c}\text { Bucarest } 26 \text { y } \\
27 / 04 / 2012\end{array}$ & $\begin{array}{l}\text { Impulsar métodos innovadores de enseñanza. } \\
\text { Responsabilidad en la garantía de calidad. Diálogo sobre } \\
\text { financiación y gobernanza. Gestión más eficiente en } \\
\text { estructuras universitarias. Reconocimiento del aprendizaje } \\
\text { no formal e informal. Aumento de tasa de culminación de } \\
\text { estudios. Movilidad en el } 3^{\circ} \text { ciclo. }\end{array}$ & \\
\hline Ereván 2015 & $\begin{array}{l}\text { Refuerzo de la cooperación entre el EEES (Espacio Europeo } \\
\text { de Educación Superior) y MENAAS (Oriente medio, África } \\
\text { del Norte y Asia). Desarrollo de proyectos conjuntos. } \\
\text { Reconocimiento mutuo de cualificaciones. Cooperación en } \\
\text { aplicación del ETCS. Desarrollo estudiantil centrado en } \\
\text { ambientes de aprendizaje. Desarrollo democrático en } \\
\text { educación e investigación. Cooperación en garantía de } \\
\text { calidad. }\end{array}$ & \\
\hline
\end{tabular}

Fuente: Elaboración propia (2018). ${ }^{1}$

Tal y como se desgrana del cuadro siguiente (cuadro 4), la aplicación e impulso del proceso de Bolonia a partir de sus criterios orientadores, implica no solo un compromiso por parte de todos los entes involucrados, sino que, además, constituye el patrón a seguir para que todo el contexto universitario esté enfocado en un cambio de modelo educativo, esta vez dicho cambio privilegia la atención al estudiante. Florido, C., Jiménez, J., y Santana, I. (2011). Un dato a resaltar es que los estados miembros al firmar su adhesión al proceso de Bolonia se comprometen a implementar en sus respectivos países todas las directrices impulsadas desde Europa, sin embargo, los mismos

\footnotetext{
${ }^{1}$ Para la elaboración de este cuadro, se analizaron los siguientes documentos:

Declaración de La Sorbona (1998)

Declaración de Bolonia (1999)

Comunicado de la reunión de ministros europeos responsables de la enseñanza superior, Praga (2001)

Comunicado de la reunión de ministros europeos responsables de la enseñanza superior, Berlín (2003)

Comunicado de la reunión de ministros europeos responsables de la enseñanza superior, Bergen (2005)

Comunicado de Londres (2007)

Comunicado de la reunión de ministros europeos responsables de la enseñanza superior, Lovaina (2009)

Declaración de Budapest y Viena sobre el Espacio Europeo de Educación Superior, (2010)

Comunicado de Bucarest (2012)

Declaración de Ereván (2015)
}

Revista de Estudios Andaluces, núm. 36 (2018) pp.98-120. e-ISSN: 2340-2776

http://dx.doi.org/10.12795/rea.2018.i36.05

cc) (i) $\ominus$

cC) Esta obra se distribuye con la licencia Creative Commons Reconocimiento-NoComercial-SinObraDerivada 4.0 Internacional (CC BY-NC-ND 4.0.) 
criterios aportan una gran responsabilidad a las universidades como cuerpos ejecutores de estos criterios y dentro de los cuales se hace mención al docente universitario.

Cuadro 4. Criterios orientadores según el Proceso de Bolonia discriminados por áreas de acción.

\begin{tabular}{|c|c|}
\hline Área & Criterio orientador según el Proceso de Bolonia \\
\hline Estudiantil & $\begin{array}{l}\text { Educación superior centrada en el estudiante. Movilidad estudiantil. } \\
\text { Aprendizaje a lo largo de la vida. } \\
\text { Mejora de la empleabilidad de los titulados. } \\
\text { Reducción de la exclusión universitaria por razones económicas. }\end{array}$ \\
\hline $\begin{array}{c}\text { Administración y } \\
\text { gobierno } \\
\text { universitario }\end{array}$ & $\begin{array}{l}\text { Políticas públicas en función del proceso de Bolonia. Promoción de cooperación } \\
\text { europea. Promoción internacional del sistema universitario. } \\
\text { Integración de la formación e investigación. Sinergia entre educación y otros } \\
\text { sectores (investigación, empresas). } \\
\text { Apoyo en decisiones financieras favorables para el proceso EEES. } \\
\text { Garantizar que las universidades cuenten con recursos necesarios. } \\
\text { Financiación pública como prioridad y desarrollo sostenible de las universidades. } \\
\text { Apertura de diálogo sobre financiación y gobernanza de la Educación Superior. } \\
\text { Planes nacionales para mejorar la calidad. } \\
\text { Dimensión social de la educación universitaria. La Universidad como servicio } \\
\text { público. } \\
\text { Reconocimiento de la autonomía académica y universitaria. } \\
\text { Desarrollo de gestión eficiente en las estructuras de las instituciones } \\
\text { universitarias. }\end{array}$ \\
\hline $\begin{array}{l}\text { Currículum } \\
\text { universitario }\end{array}$ & $\begin{array}{l}\text { Impulso del ECTS (conocido como el crédito europeo) EEES estructurado en } 3 \\
\text { ciclos. } \\
\text { Promoción del aprendizaje de idiomas } \\
\text { Máster de corta duración y Doctorado más extenso. Red de trabajo en el nivel } \\
\text { doctoral. Formación interdisciplinar en los estudios doctorales. } \\
\text { Cooperación europea en el aseguramiento de la calidad. } \\
\text { Estudios de 1er ciclo de } 3 \text { años mínimo. } \\
\text { Adopción de un sistema de titulaciones reconocible y comparable. } \\
\text { Programas conjuntos y planes de estudio flexibles. } \\
\text { Aprendizaje sobre el medio ambiente. Reconocimiento del aprendizaje no formal } \\
\text { e informal. Impulsar métodos innovadores de enseñanza. }\end{array}$ \\
\hline Personal do & $\begin{array}{l}\text { Movilidad docente. Planes de formación y actualización docente por parte de las } \\
\text { universidades. }\end{array}$ \\
\hline
\end{tabular}

Fuente: Elaboración propia (2018).

La referencia al docente universitario se hace en virtud de que, aunque no forme parte de los objetivos de esta investigación, si que es cierto que el docente es en definitiva, el que debe llevar a la práctica en las aulas universitarias este nuevo modelo educativo, no obstante, no se ha identificado un criterio o política expresa que asegure un proceso de formación en cuanto a la didáctica necesaria de cara a nuevas formas de enseñar, solo se hace referencia a que esta actividad esté en manos de las propias universidades. Si bien es cierto que dentro de estos criterios se hace mayor énfasis en el estudiante como centro de atención, las iniciativas de actualización y formación docente han sido generadas mayoritariamente por las universidades, es decir, por los órganos ejecutivos de la universidad. Toledo Lara, G. (2018); Vega Gil, L. (2017). Esta afirmación posiblemente pueda ser un aspecto que analizar de cara a la integración efectiva de todos los actores involucrados en este proceso reformista.

Revista de Estudios Andaluces, núm. 36 (2018) pp. 98-120. e-ISSN: 2340-2776

http://dx.doi.org/10.12795/rea.2018.i36.05

Esta obra se distribuye con la licencia Creative Commons Reconocimiento-NoComercial-SinObraDerivada 4.0 Internacional (CC BY-NC-ND 4.0.) 
Al referirnos a los estudiantes, entendemos que son aquellos que están matriculados en una titulación oficial, tal y como se establece en la Guía de uso del ECTS (ECTS = Sistema de Transferencia del Crédito Europeo), el estudiante es la "persona matriculada en un programa académico formal". Por lo tanto, el término correcto es estudiante y se entiende que es un estudiante universitario. Ahora bien, con respecto a la implantación de los criterios de Bolonia, una visión global nos la ofrece el siguiente cuadro (cuadro 5) en la que se señala dicho grado de implantación en el $1^{\circ}$ y $2^{\circ}$ ciclo a nivel europeo:

Cuadro 5. Grado de implantación del primer y segundo ciclo según los criterios de Bolonia $2014 / 15$.

\begin{tabular}{|l|l|}
\hline \multicolumn{1}{|c|}{ Criterio } & \multicolumn{1}{|c|}{ Países } \\
\hline $\begin{array}{l}\text { Al menos el 90\% de todos los estudiantes } \\
\text { están matriculados en el sistema de dos } \\
\text { ciclos de acuerdo con los principios de } \\
\text { Bolonia. }\end{array}$ & $\begin{array}{l}\text { Albania, Alemania, Armenia, Austria, Azerbaiyán, Bélgica, } \\
\text { Bosnia - Herzegovina, Bulgaria, Croacia, Eslovaquia, } \\
\text { España, Finlandia, Francia, Georgia, Grecia, Hungría, } \\
\text { rlanda, Islandia, Italia, Letonia, Liechtenstein, Lituania, } \\
\text { Macedonia, Malta, Moldavia, Montenegro, Polonia, } \\
\text { República Checa, Rumanía, Rusia, Suecia, Suiza, Turquía. }\end{array}$ \\
\hline $\begin{array}{l}70 \% \text { - 89\% de todos los estudiantes están } \\
\text { matriculados en el sistema en dos ciclos } \\
\text { según Bolonia. }\end{array}$ & $\begin{array}{l}\text { Eslovenia, Estonia, Luxemburgo, Noruega, Países bajos, } \\
\text { Portugal, } \\
\text { Reino Unido, Vaticano, }\end{array}$ \\
\hline $\begin{array}{l}50 \% \text { - 69\% de todos los estudiantes están } \\
\text { matriculados en el sistema en dos ciclos } \\
\text { según Bolonia. }\end{array}$ & Andorra. \\
\hline $\begin{array}{l}25 \% \text { - } 49 \% \text { de todos los estudiantes están } \\
\text { matriculados en el sistema de dos ciclos } \\
\text { según Bolonia. }\end{array}$ & 0 \\
\hline $\begin{array}{l}\text { Menos del } 25 \% \text { de todos los estudiantes } \\
\text { están matriculados en una titulación } \\
\text { estructurada en dos ciclos según Bolonia. }\end{array}$ & 0 \\
\hline $\begin{array}{l}\text { Datos no disponibles } \\
\text { Fuente: Elabrania }\end{array}$ \\
\hline
\end{tabular}

Fuente: Elaboración propia (2018).

Respecto al grado de implantación de Bolonia en el $1^{\circ}$ y $2^{\circ}$ ciclo, en 33 países existe un $90 \%$ de implantación, mientras que 8 países cuentan con un 70/80 \%. Es de señalar que la adopción del proceso de Bolonia por parte de los países no implica que en todas las universidades o grados se desarrolle dicho proceso, por ejemplo, en Reino Unido y en Italia no todas las universidades implementan el proceso de Bolonia, inclusive en una misma universidad pueden existir grados con o sin adopción de Bolonia. En este mismo orden de ideas, y dentro del EEES, el tercer ciclo de la estructura de Bolonia (programas de doctorado) normalmente representan menos del $5 \%$ del total de estudiantes matriculados. Las excepciones son Finlandia, Eslovaquia, la República Checa, Luxemburgo, Alemania y Austria.

Sobre la escala de calificación utilizada para representar cuantitativamente el resultado del aprendizaje en las titulaciones analizadas, a nivel europeo no existe un único patrón establecido, aunque 11 países han adoptado la escala de 0 al 10 (siendo 10 la máxima calificación). Otras escalas encontradas son las siguientes: 0/5 (siendo 5 la máxima calificación) 5 países, 0/20 (siendo 20 la Revista de Estudios Andaluces, núm. 36 (2018) pp.98-120. e-ISSN: 2340-2776 http://dx.doi.org/10.12795/rea.2018.i36.05 
máxima calificación) 4 países. Escala cualitativa, 3 países (Suecia, Eslovaquia y Malta), y el resto de los países cuentan con una variedad de escalas: $2 / 5,0 / 100,0 / 80,00 / 12$, entre otras escalas.

Otro de los aspectos analizados, es el rango de horas por año académico. A nivel general y según las orientaciones acordadas en Europa, habitualmente la carga de trabajo de un estudiante está entre 1500 y 1800 horas por año o curso académico, con lo cual, un crédito es el equivalente a 25/30 horas de trabajo. Por lo tanto, 60 créditos ECTS corresponden a un año académico a tiempo completo aplicable a todos los niveles que conforman el sistema de educación superior.

Sin embargo, dentro de los países miembros del proceso de Bolonia no existe un consenso generalizado en este particular. Por ejemplo, Bélgica (solo comunidad flamenca), Suiza, Chipre, República Checa, Grecia, España, Polonia, Eslovenia y Turquía tienen entre 1500 y 1800 horas por año académico y entre $25 / 30$ horas por crédito. Por otro lado, Bélgica (comunidad francesa) cuenta con 1440 horas/año académico y 24 horas/crédito. Otros casos observables son: Rumanía (1520/1640 horas/año académico y $25 / 27$ horas/crédito), Austria, Italia y Malta (1500 horas/año académico y 25 horas/crédito), Dinamarca, Finlandia, Francia, Hungría y Países Bajos (1600 /1800 horas/año académico y entre $25,27,28$ y 30 horas/crédito).

A nivel europeo se ha acordado que las cualificaciones del primer ciclo normalmente incluyan 180/240 créditos ECTS, sin embargo, no existe uniformidad en cuanto a esta disposición. A partir de los datos expuestos en el cuadro 7, se evidencia que a nivel europeo existe una tendencia marcada en diseñar estos grados con menos de 240 ECTS, es decir, entre 165 y 198 ECTS, con lo cual, de 47 países miembros del proceso de Bolonia, 28 de ellos han establecido que al menos estos grados tengan una duración alrededor de los tres años, es decir, el 59,57 \% respecto al total. Estas proporciones sugieren que efectivamente, los grados tienen una duración de tres años, pero no todos tienen la misma cantidad de créditos ECTS, con lo cual, se puede afirmar que no todas las titulaciones se configuran igual, ni funcionan de la misma manera. Tampoco existen planes de estudios idénticos entre los países miembros del EEES. Castillo, S. (2017); Masjuan, J.M., y Troiano, H. (2018). Este aspecto también dificulta la armonización de los sistemas universitarios ya que, al no contar con un criterio único, el proceso administrativo para el reconocimiento y la transferencia de ECTS no podrá desarrollarse fluidamente. Por lo tanto, se requiere hacer la conversión de las calificaciones para expresarlas en la escala de la universidad de destino en el caso de que se produzca movilidad dentro de Europa por parte de los estudiantes.

El reconocimiento de créditos es el proceso llevado a cabo por una institución universitaria, la cual certifica que los resultados de aprendizaje alcanzados y evaluados en otra institución satisfacen (parcial o totalmente) los requerimientos de un programa determinado. La transferencia de créditos es otro proceso igualmente llevado a cabo por una institución universitaria para trasladar los créditos otorgados en un contexto determinado (programa/país/universidad) y reconocerlos en otro contexto para obtener una titulación oficial. ECTS User's guide. (2011). Sin embargo, si no existe un criterio común asumido por los estados que pueda garantizar tanto el reconocimiento de créditos como su transferencia a nivel universitario, la armonización parece que, de momento, no es una práctica totalmente estandarizada en el territorio europeo. 
Es de señalar que, de las universidades analizadas, un grupo de ellas (11 en psicología y 12 en biología) ambos grados tienen 240 ECTS representando el $23,40 \%$ y el 25, $53 \%$ respectivamente (Armenia, Bulgaria, Bosnia - Herzegovina, Chipre, República Checa, Grecia, España, Georgia, Croacia, Lituania, Montenegro, Macedonia, Rusia, Turquía y Ucrania). También existen otras particularidades, por ejemplo, en Bosnia - Herzegovina, la Universidad de Sarajevo tiene el grado de psicología con 180 ECTS, pero a la vez tiene el grado de biología con 240 ECTS. (cuadro 6). En la Universidad Masaryk (República Checa) el mismo grado de biología tiene doble asignación de créditos: un grado con 180 ECTS y el mismo grado con 240 ECTS. Este mismo caso se repite en la Universidad de Montenegro (Montenegro) y en la Universidad de Zagreb (Croacia) pero con el grado de psicología. Por otro lado, la Universidad de Roma (Italia) al menos en los grados de psicología y biología, utiliza el CFU (crédito formativo universitario) en lugar de usar el crédito ECTS. En el Reino Unido, aunque dicho país es miembro del proceso de Bolonia, por ejemplo, la Universidad de Oxford (psicología) y la Universidad de Cambridge (biología) no se organiza en créditos ECTS, aunque estos grados duran 3 años.

Cuadro 6. Distribución de ECTS en Psicología y Biología - EEES.

\begin{tabular}{|l|c|c|}
\hline & Psicología & Biología \\
\hline $\mathrm{n}^{\circ}$ de países que tienen este grado con 240 ECTS & 11 & 12 \\
\hline $\mathrm{n}^{\circ}$ de países con menos de 240 ECTS en este grado (entre 165 y 198) & 28 & 27 \\
\hline $\mathrm{n}^{\circ}$ de países con más de 240 ECTS en este grado & 2 & 0 \\
\hline $\mathrm{n}^{\circ}$ de países que tienen este grado con 180 y 240 ECTS simultáneamente & 1 & 2 \\
\hline $\begin{array}{l}\mathrm{n}^{\circ} \text { de países que pertenecen a Bolonia, pero no todas las } \\
\text { universidades/grados adoptan el proceso de Bolonia }\end{array}$ & 1 & 2 \\
\hline
\end{tabular}

Fuente: Elaboración propia (2018) con datos tomados de las páginas oficiales de cada universidad.

Respecto al uso de los resultados de aprendizaje, es importante destacar que "para poder incorporar adecuadamente los resultados del aprendizaje y de los procesos de evaluación es condición indispensable cambiar el paradigma, desde un modelo de aprendizaje centrado en el profesor a otro centrado en el alumno" (Comisión Europea, 2015, 73). Esto nos indica que la formación dirigida al profesorado universitario es determinante al momento de considerar y utilizar los resultados del aprendizaje ya que "se destaca la necesidad de la actualización docente para el desarrollo de EEES. Difícilmente puede llevarse a cabo una reforma educativa, sin que ello pase por una actualización del profesorado implicado" (Rodríguez, M., Mateos, M., y Huertas, J. 2011, 247).

A nivel general, se observa una tendencia respecto a sugerir el uso de los resultados del aprendizaje en función del desarrollo curricular. Este tipo de orientaciones están incluidas en los marcos normativos de 22 sistemas educativos dentro del EEES. Por otro lado, otros 16 estados fomentan el uso de los resultados por medio de una serie de instrucciones o recomendaciones. Se destacan los casos de Albania, Eslovaquia, Hungría, Portugal y Suiza en los que no se evidencia algún tipo de orientación proveniente del nivel central, respecto a asumir un modelo basado en los resultados del aprendizaje.

En este orden de ideas, el uso de los resultados del aprendizaje en la evaluación de los estudiantes no está totalmente desarrollado ya que la importancia del uso de los resultados del aprendizaje en

Revista de Estudios Andaluces, núm. 36 (2018) pp.98-120. e-ISSN: 2340-2776 http://dx.doi.org/10.12795/rea.2018.i36.05

(c) (i) $\ominus$

CC. Esta obra se distribuye con la licencia Creative Commons Reconocimiento-NoComercial-SinObraDerivada 4.0 Internacional (CC BY-NC-ND 4.0.) 
los procedimientos de evaluación de los estudiantes no es una práctica tan comúnmente desarrollada y desde luego este factor nos sugiere que dicha importancia no ha sido comprendida en su totalidad.

Tal y como señalan Rodríguez, M., Mateos, M. y Huertas, J., $(2011,247)$ "la mayor parte de los trabajos empíricos relativos a las trasformaciones que conlleva la aplicación del ECTS se centran en la estimación de la carga de trabajo de alumnos y en las equivalencias en las calificaciones de los estudiantes". Por lo tanto, resulta difícil lograr un cambio hacia un enfoque en el que se centre la atención hacia el estudiante basado en los resultados del aprendizaje si no se logra realizar el análisis de los resultados de ese aprendizaje y de los créditos ETCS que están asociados a dichos resultados. A nivel europeo (cuadro 7) se puede asegurar que la tendencia se inclina mayoritariamente a que los créditos se asignan en función de los resultados del aprendizaje alcanzados y tomando en cuenta la carga de trabajo por parte de los estudiantes. Sin embargo, también se observa un grupo de países que establecen los créditos a partir de la combinación entre el trabajo dirigido al estudiante y las horas de contacto entre el estudiante y el profesor.

Cuadro 7. Criterios para la asignación de créditos ECTS en la mayoría de las instituciones de educación superior 2013/14.

\begin{tabular}{|l|l|}
\hline \multicolumn{1}{|c|}{ Criterios } & \multicolumn{1}{c|}{ Países } \\
\hline $\begin{array}{l}\text { Combinación de los resultados del } \\
\text { aprendizaje y de la carga de trabajo para } \\
\text { el estudiante }\end{array}$ & $\begin{array}{l}\text { Alemania, Andorra, Armenia, Austria, Azerbaiyán, Bélgica, } \\
\text { Bulgaria, Chipre, Dinamarca, Estonia, Finlandia, Francia, } \\
\text { Georgia, Grecia, Irlanda, Islandia, Italia, Kazajistán, Letonia, } \\
\text { Lituania, Luxemburgo, Macedonia, Moldavia, Malta, } \\
\text { Noruega, Países Bajos, Polonia, Portugal, Rusia, Rumanía, } \\
\text { Serbia, Suecia, Suiza, Turquía. }\end{array}$ \\
\hline Solo resultados del aprendizaje & Reino Unido (Inglaterra e Irlanda del norte) \\
\hline Solo carga de trabajo del estudiante & Albania, Eslovenia, Liechtenstein. \\
\hline $\begin{array}{l}\text { Combinación de la carga de trabajo para } \\
\text { el alumno y de las horas de contacto } \\
\text { estudiante/profesor }\end{array}$ & $\begin{array}{l}\text { Bosnia - Herzegovina, Croacia, Eslovaquia, Estado } \\
\text { Vaticano, España, Hungría, Montenegro. }\end{array}$ \\
\hline Otros & República Checa \\
\hline Datos no disponibles & Ucrania \\
\hline
\end{tabular}

Fuente: Elaboración propia (2018) con datos tomados de: Comisión Europea/EACEA/Eurydice, 2015.

Por ejemplo, en el caso de Albania, Eslovenia y Liechtenstein, se asignan los créditos en función solo de la carga de trabajo para el estudiante. Por otro lado, en Reino Unido se conceden los créditos solamente en base a la consecución de los resultados del aprendizaje. Por su parte, en la República Checa los resultados del aprendizaje pueden combinarse con la carga de trabajo o con las horas de contacto entre el estudiante y el profesor. Con este panorama se puede identificar que, si bien es cierto que existe una tendencia mayoritaria hacia una sola metodología para la asignación de los créditos ETCS, aún existen diferencias considerables entre un número importante de estados miembros. Una de las consecuencias de esta realidad posiblemente sea la todavía imposibilidad de que el reconocimiento de los créditos y las titulaciones entre los países miembros, de momento sea una tarea pendiente. 
Una de las iniciativas impulsadas por la Comisión Europea que merece ser analizada, es la solicitud hecha a los países para que otorguen puntuaciones a los diversos componentes del aprendizaje centrado en el estudiante. Los resultados permiten identificar dos grupos ${ }^{2}$ : el grupo " $A$ " conformado por 41 países y el grupo " $B$ " conformado por 6 países. Ahora bien, los componentes del aprendizaje centrados en el estudiante fueron los siguientes: a) Resultados del aprendizaje, b) Evaluación basada en los resultados de aprendizaje, c) Evaluación de la práctica docente por parte de los estudiantes, d) Formación pedagógica del personal, e) Aprendizaje autónomo, f) Reconocimiento del aprendizaje previo, g) Ratio estudiante/personal, h) Aprendizaje en grupos reducidos.

Figura 1. Importancia concedida por los países del EEES a los aspectos del modelo educativo centrado en el estudiante.

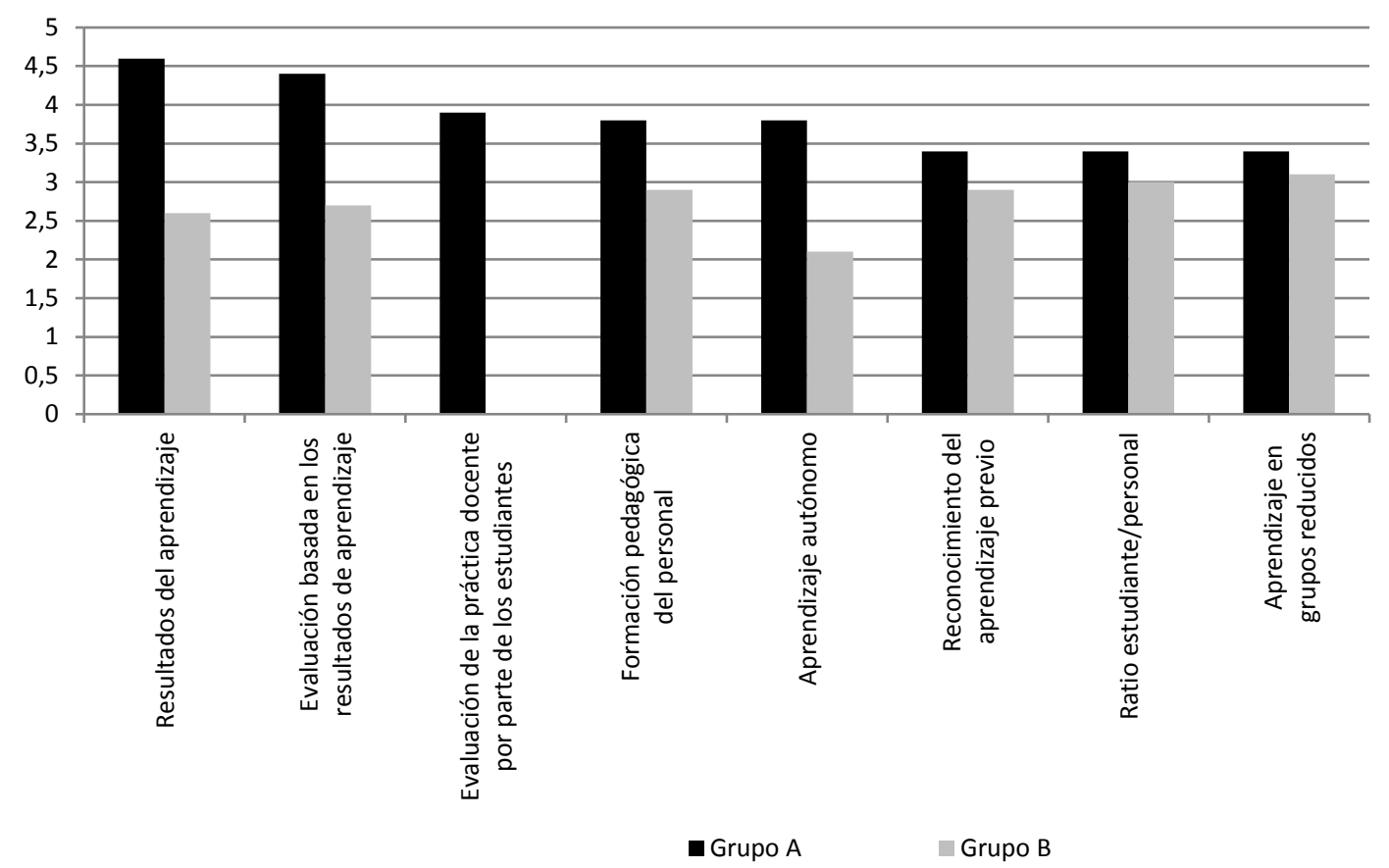

Fuente: Elaboración propia (2018) con datos tomados de: Comisión Europea/EACEA/Eurydice, 2015.

De los resultados anteriores, (figura 1) se pueden señalar las siguientes consideraciones: Para el grupo " $\mathrm{A}$ ", todos los componentes del aprendizaje son altamente valorados, destacándose los resultados del aprendizaje y la evaluación basada en los resultados del aprendizaje. En segundo lugar, se valoró la evaluación de la práctica docente por parte de los estudiantes, la formación pedagógica del personal y el aprendizaje autónomo. Por otra parte, en el grupo "B", el aspecto del aprendizaje centrado en el estudiante no muestra tanta utilidad como modelo educativo. En este grupo, los elementos peor valorados fueron los siguientes: 1) la evaluación de la práctica docente

\footnotetext{
2 El grupo "A" conformado por: Alemania, Andorra, Armenia, Austria, Azerbaiyán, Bélgica, Bosnia - Herzegovina, Bulgaria, Chipre, Croacia, Dinamarca, Eslovaquia, Estonia, España, Finlandia, Francia, Georgia, Grecia, Hungría, Irlanda, Islandia, Italia, Kazajistán, Letonia, Lituania, Luxemburgo, Macedonia, Malta, Moldavia, Montenegro, Noruega, Países Bajos, Polonia, Portugal, Reino Unido, Rusia, Rumanía, Serbia, Suecia, Suiza, Turquía.

El grupo “B” conformado por: Albania, Estado Vaticano, Estonia, Liechtenstein, República Checa y Ucrania.

Revista de Estudios Andaluces, núm. 36 (2018) pp.98-120. e-ISSN: 2340-2776
}

http://dx.doi.org/10.12795/rea.2018.i36.05

cc) (i) $\odot$ 
por parte de los estudiantes (valorado con un cero), 2) el aprendizaje autónomo y 3) el uso de los resultados del aprendizaje. Por lo tanto, se "demuestra que en aquellos sistemas en los que las leyes o documentos estratégicos no hacen mención del aprendizaje centrado en el estudiante no se concede tanta relevancia a este enfoque pedagógico" (Comisión Europea, 2015, 76).

Más allá del análisis enfocado a las titulaciones de psicología y biología, resulta relevante reconocer el número de estudiantes matriculados en el EEES para obtener una visión de conjunto de la magnitud de todo el sistema universitario europeo. Por un lado, tenemos 960 estudiantes en Liechtenstein, por otro, tenemos un grupo conformado por cuatro países que representan más del $54 \%$ del total de estudiantes (Ucrania, Reino Unido, Alemania y Turquía). Junto a estos, Italia, España, Polonia y Francia cuentan con más de 1.900 .000 estudiantes. También es de señalar que en 18 países del EEES el número de estudiantes no llega a los 200.000 , mientras que Rusia es el país con mayor población estudiantil con casi 8 millones de estudiantes. (figura 2).

Se puede señalar de acuerdo con el informe de la Comisión Europea $(2015,28)$, que "en todo el EEES hay aproximadamente 37,2 millones de estudiantes matriculados en educación superior". Esta cifra nos puede sugerir la idea de que estamos ante un mega sistema de educación superior sin embargo el número de personas que tienen la titulación necesaria para ingresar a la universidad, las políticas internas de admisión, la duración de los estudios propuesta y la duración real, la situación laboral de los estudiantes y sus condiciones socioeconómicas hacen que la proporción del número de estudiantes sea sumamente desigual entre los 47 países pertenecientes al EEES por lo tanto, este dato nos señala las particularidades demográficas de la región. Además de esto, el número de estudiantes matriculados es un aspecto para observar de cara al impulso de políticas dirigidas al sector universitario que puedan garantizar, entre otros aspectos, la financiación, la movilidad y el intercambio entre los países miembros.

A partir de la observación de los datos respectivos, es decir, al analizar cada una de las 55 universidades señaladas inicialmente, se extraen los resultados que aquí se exponen. Por lo tanto, y como resultado de la investigación realizada, se puede asegurar que cerca del $60 \%$ de los países miembros del EEES consideran las proporciones demográficas en las estrategias a seguir de cara al desarrollo y evolución del sistema de educación superior. Es de destacar el interés en este particular ya que se ha hecho evidente la disminución del número de jóvenes y el impacto de esto en la financiación de la educación superior, sin dejar de reconocer la necesidad de una preparación adecuada de cara a la necesidad de una formación en competencias ante una población que envejece y ante la llegada de estudiantes de edad mayor con respecto a los jóvenes. Estas afirmaciones son más palpables de parte de las Universidades, las cuales, siempre han mostrado una posición crítica respecto a asumir modelos educativos poco contextualizados.

Aunque pueda considerarse un indicador cualitativo, respecto a la titulación que otorgan las universidades también existen algunas diferencias en el contexto europeo: mientras que en el caso español se otorga el título de "grado", en los países y universidades investigadas, el 78, 72 \% otorga el título de "bachelor". Aunque es una proporción mayoritariamente expandida, existen además otras particularidades: Andorra (Bátxelor), Austria (Bachelor of Science) España y Polonia (Grado), 
Francia (Licence), Croacia (Bachelor/Baccalaurea), Italia (Laurea), Portugal y Rusia (Licenciado), Rumanía (Licenta), Turquía (Graduado), Estado Vaticano (Baccalaureato).

Figura 2. Número de estudiantes matriculados en educación superior $2015\left(^{*}\right)$.

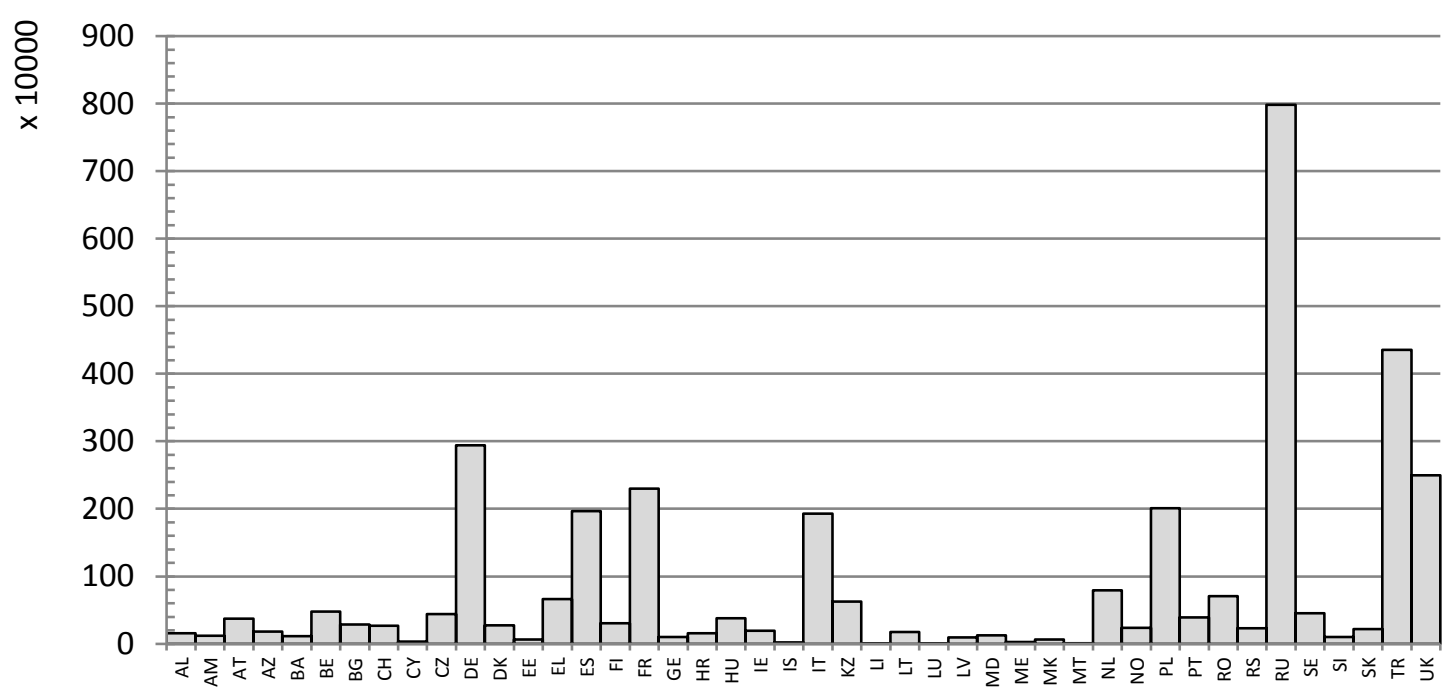

\begin{tabular}{|l|l|l|l|l|l|}
\hline AD & Andorra & FI & Finlandia & MK & Macedonia \\
\hline AL & Albania & FR & Francia & MT & Malta \\
\hline AM & Armenia & GE & Georgia & NL & Países Bajos \\
\hline AT & Austria & HR & Croacia & NO & Noruega \\
\hline AZ & Azerbaiyán & HU & Hungría & PL & Polonia \\
\hline BA & Bosnia-Herzegovina & IE & Irlanda & PT & Portugal \\
\hline BE & Bélgica & IS & Islandia & RO & Rumanía \\
\hline BG & Bulgaria & IT & Italia & RS & Serbia \\
\hline CH & Chipre & KZ & Kazajistán & RU & Rusia \\
\hline CZ & República Checa & LI & Liechtenstein & SE & Suecia \\
\hline DE & Alemania & LT & Lituania & SI & Eslovenia \\
\hline DK & Dinamarca & LU & Luxemburgo & SK & Eslovaquia \\
\hline EE & Estonia & LV & Letonia & TR & Turquía \\
\hline EL & Grecia & MD & Moldavia & UA & Ucrania \\
\hline ES & España & ME & Montenegro & UK & Reino Unido \\
\hline & & & & VA & Estado Vaticano (**) \\
\hline
\end{tabular}

$\left(^{*}\right)$ Se incluye el $1^{\circ}, 2^{\circ}$ y $3^{\circ}$ ciclo.

$\left({ }^{* *}\right)$ Dato no disponible

Fuente: Elaboración propia (2018) con datos tomados de: Comisión Europea/EACEA/Eurydice, 2015.

\section{CONCLUSIONES}

A lo largo del análisis de los documentos producidos en el marco del proceso de Bolonia, se puede encontrar un hilo conductor que permanentemente evoca una adaptación de la Universidad a la sociedad. Es decir, al parecer Bolonia apuesta por una Universidad socialmente pertinente y que además pueda cualificar a sus estudiantes al demandante mercado laboral. En este mismo orden de Revista de Estudios Andaluces, núm. 36 (2018) pp.98-120. e-ISSN: 2340-2776 http://dx.doi.org/10.12795/rea.2018.i36.05

(c) (†) $\ominus$

cC. EY NG ND Esta obra se distribuye con la licencia Creative Commons Reconocimiento-NoComercial-SinObraDerivada 4.0 Internacional (CC BY-NC-ND 4.0.) 
ideas, impera desde un punto de vista exógeno y endógeno de la Universidad cierta tendencia a reafirmar el deber adaptativo de la institución universitaria, como subterfugio para la búsqueda de una Universidad progresista y desarrollista.

Sin embargo, los criterios orientadores del proceso de Bolonia también cuentan con cierto influjo ideológico de parte de organismos internacionales que buscan, ante todo, un talento humano formado a partir de los requerimientos productivos. Por ejemplo, el Banco Mundial, la Organización Mundial del Comercio y la Organización para la Cooperación y el Desarrollo han ejercido influencia ideológica en ciertos aspectos que contextualizan a Bolonia como proceso. De allí se deriva la discusión de parte de los detractores de esta corriente reformista al asegurar que, con esta reforma, se busca el lado mercantil o economicista de la Universidad en Europa.

También es de destacar que todos los criterios identificados no son adoptados de forma automática o sincrónica por los estados signatarios. García-Berro, E., Dapia, F., Amblàs, G., Bugeda, G., y Roca, S. (2009). Cada estado intenta adaptar estas líneas a sus realidades y contextos, con lo cual, se ha observado que existen múltiples interpretaciones y aplicaciones sobre un mismo criterio sin dejar de reconocer que, generalmente, los gobiernos y las universidades tienen interpretaciones diferentes sobre lo que se acuerda a nivel europeo en materia universitaria. Mientras esto ocurre, se acentúa la necesidad de reducir la separación entre las cualificaciones profesionales de los titulados y la demanda laboral, ya que el desarrollo del EEES no parece haber arrojado los mejores resultados en cuanto a reducir la inadecuación de las cualificaciones en la Unión Europea.

Uno de los principios impulsados en el EEES es la transferencia de créditos, el reconocimiento de estos y la movilidad estudiantil. Para lograr lo anterior, es importante una efectiva armonización de los sistemas universitarios nacionales de tal manera que esto pueda llevarse a cabo de una manera fácil, sincronizada, y que pueda garantizar la reducción de los procedimientos y las diferencias en la administración curricular de los grados.

A partir de los datos obtenidos de las 55 universidades que se han investigado para la realización de este trabajo, se evidencia que no existen coincidencias en la asignación de los ECTS. Esto ocasiona entre otros efectos, que la movilidad del estudiante se vea afectada ya que, al no existir un patrón común entre los países miembros, el proceso de reconocimiento de créditos no se haga de forma ágil al necesitarse todo un proceso de revisión y cálculo de los créditos obtenidos para verificar si los mismos son equiparables con las características formativas de la institución receptora. También es importante que las personas encargadas de estos procesos estén suficientemente preparadas en cuanto a la administración curricular en el contexto de Bolonia.

Por lo tanto, la escala de calificación utilizada, el grado de implantación de Bolonia en el 1ํ y 2ำ ciclo, el rango de horas por curso académico y por titulación, el número de ECTS en los grados investigados, la duración de las titulaciones y el uso de los resultados de aprendizaje no es igual en todo el EEES, con lo cual, la armonización de los sistemas universitarios en Europa de momento no es una realidad plena, aunque si es justo reconocer los avances y logros alcanzados en este particular. García-Berro, E., Dapia, F., Amblàs, G., Bugeda, G., y Roca, S. (2009). 
La reducción del número de estudiantes y las contracciones presupuestarias dirigidas al sector universitario, producen su decrecimiento ya que, al ser la universidad europea mayoritariamente pública, se depende en gran medida de la financiación por parte del gobierno central y regional. Todo ello en detrimento del avance de la investigación universitaria como parte sustancial del quehacer de la Universidad, a pesar de que, como criterio orientador, Bolonia apunta la necesidad de una adecuada financiación universitaria. En este punto y a propósito de esta investigación es importante recordar que, desde Europa los informes oficiales no se generan anualmente, lo cual trae como consecuencia que, al analizar datos y cifras, estos se corresponden a 2 o 3 años atrás y esto puede convertirse en una limitante, aunque tales informes se expresen de forma sumamente completa y detallada.

Finalmente, la visión del continente europeo exige la necesidad de considerar todo un proceso reformista que en efecto pueda reconocer las particularidades de cada estado miembro, pero, además, que cada estado miembro asuma como política interna la adecuación requerida en materia de administración curricular de forma tal, que la armonización y la movilidad pueda llevarse a cabo sin mayores contratiempos buscando siempre el beneficio del estudiante y lógicamente de la Universidad.

\section{REFERENCIAS}

Agencia Nacional de Evaluación de la Calidad y Acreditación (2018). Bucharest Communiqué. Making the Most of Our Potential: Consolidating the European Higher Education Area (2012). Recuperado de <http://www.aneca.es/Actividad-internacional/Documentos-internacionales-dereferencia/Comunicados-de-los-ministros-europeos > [25 de enero de 2018].

Agencia Nacional de Evaluación de la Calidad y Acreditación (2018). Declaración de Berlín. Comunicado oficial de la Conferencia de Ministros responsables de Educación Superior en Berlín el 19 de septiembre de 2003. Recuperado de <http://www.aneca.es/Actividadinternacional/Documentos-internacionales-de-referencia/Comunicados-de-los-ministroseuropeos> [16 de enero de 2018].

Agencia Nacional de Evaluación de la Calidad y Acreditación (2018). London Communique. Towards the European Higher Education Area: responding to challenges in a globalised world 2007. Recuperado de <http://www.aneca.es/Actividad-internacional/Documentos-internacionales-dereferencia/Comunicados-de-los-ministros-europeos> [16 de enero de 2018].

Agencia Nacional de Evaluación de la Calidad y Acreditación (2018). Lovaina Comuniqué. Communiqué of the Conference of European Ministers Responsible for Higher Education, Leuven and Louvain-la-Neuve 2009. Recuperado de <http://www.aneca.es/Actividadinternacional/Documentos-internacionales-de-referencia/Comunicados-de-los-ministroseuropeos> [16 de enero de 2018]. 
Agencia Nacional de Evaluación de la Calidad y Acreditación (2018). Prague Declaration. Towards the European Higher Education Area. Communiqué of the meeting of European Ministers in charge of Higher Education 2001. Recuperado de <http://www.aneca.es/Actividadinternacional/Documentos-internacionales-de-referencia/Comunicados-de-los-ministroseuropeos> [16 de diciembre de 2017].

Alonso-Sáez, I., y Arandia-Loroño, M. (2017). 15 años desde la Declaración de Bolonia. Desarrollo, situación actual y retos del Espacio Europeo de Educación Superior. Revista iberoamericana de educación superior, vol. 8 (23), pp. 199-213.

Castillo, S. (2017). La educación superior después de Bolonia: balance y perspectivas. Horizontes Sociológicos, (9), pp. 91-97.

Comas, M., y de Bofarull, I. (2014). El EEES, principios fundamentales: convergencia, movilidad y reconocimiento. RIESED-Revista Internacional de Estudios sobre Sistemas Educativos, 2(3), pp. 2336.

Comisión Europea. (2011). ECTS User's guide. Madrid, España: Organismo Autónomo Programas Educativos Europeos.

Comisión Europea/EACEA/Eurydice (2015). El Espacio Europeo de Educación Superior en 2015: Informe sobre la implantación del Proceso de Bolonia. Luxemburgo: Oficina de Publicaciones de la Unión Europea. Recuperado de <https://sede.educacion.gob.es/publiventa/el-espacio-europeode-educacion-superior-en-2015-informe-sobre-la-implantacion-del-proceso-de-bolonia /educacion -superior-europa/20624> [16 de diciembre de 2017].

De Garay, A. (2012). Los diez primeros años del Proceso de Bolonia en la educación superior en Europa. Revista de la Educación Superior, vol.162, pp. 113-126.

EEES Universidad de Sevilla (2010). Comunicado de Bergen (2005). Recuperado de <http://institucional.us.es/eees/formacion/html/bergen_declaracion.htm> [19 de enero de 2018].

Espacio Europeo de Educación Superior (2018). Declaración de La Sorbona (1998). Declaración Conjunta para la Armonización del Diseño del Sistema de Educación Superior Europeo a cargo de los Ministros Representantes de Francia, Alemania, Reino Unido e Italia. Recuperado de <http://tecnologiaedu.us.es/mec2011/htm/mas/2/21/15.pdf> [19 de enero de 2018].

European Higher Education Area (2010). Budapest-Vienna Declaration on the European Higher Education Area. Recuperado de <http://www.ehea.info/cid101033/budapest-viennadeclaration.html>[19 de enero de 2018].

Ferro, C., Martínez, A., y Otero, M. (2009). Ventajas del uso de las TICs en el proceso de enseñanzaaprendizaje desde la óptica de los docentes universitarios españoles. EDUTEC. Revista electrónica de Tecnología educativa, 29, pp. 1-12. doi: https://doi.org/10.21556/edutec.2009.29.451

Revista de Estudios Andaluces, núm. 36 (2018) pp. 98-120. e-ISSN: 2340-2776

http://dx.doi.org/10.12795/rea.2018.i36.05

Esta obra se distribuye con la licencia Creative Commons Reconocimiento-NoComercial-SinObraDerivada 4.0 Internacional (CC BY-NC-ND 4.0.) 
Florido, C., Jiménez, J., y Santana, I. (2011). Obstáculos en el camino hacia Bolonia: efectos de la implantación del Espacio Europeo de la Educación Superior (EEES) sobre los resultados académicos. Revista de educación, (354), pp. 327-328.

García-Berro, E., Dapia, F., Amblàs, G., Bugeda, G., y Roca, S. (2009). Estrategias e indicadores para la evaluación de la docencia en el marco del EEES. Revista de investigación en educación, (6), pp. 142-152.

Garmendia, C. (2016). De la construcción del Espacio Europeo de Educación Superior, "Bolonia” y otros demonios. La Cuestión Universitaria, (5), pp. 3-8.

Masjuan, J. M., y Troiano, H. (2018). Incorporación de España al espacio europeo de educación superior: el caso de una universidad catalana. Calidad en la Educación, (31), pp. 124-142.

Ministerial Conference and Fourth Bologna Policy Forum EHEA (2015). Statement of the Fourth Bologna Policy Forum Yerevan 14 - 15 May 2015. Recuperado de <http://bolognayerevan2015.ehea.info/pages/view/documents > [19 de enero de 2018].

Morín, E. (2012). De la reforma universitaria. Unipluriversidad, 1, pp. 74-79.

Observatory Magna Charta Universitatum (2017). Magna Charta Universitatum. (1988). Recuperado de <http://www.magna-charta.org/magna-charta-universitatum> [19 de enero de 2018].

Parlamento Europeo (2015). Resolución del Parlamento Europeo, de 28 de abril de 2015, sobre el seguimiento de la aplicación del Proceso de Bolonia. Recuperado de <http://eurlex.europa.eu/legal-content/ES/TXT/?uri=CELEX\%3A52015IP0107> [19 de enero de 2018].

Rabe, B. (2017). La incertidumbre de la reforma universitaria. Revista Análisis de la realidad nacional, 6, pp. 136-150.

Rodríguez, M., Mateos, M., y Huertas, J. (2011). Aplicación de la metodología del sistema europeo de transferencia de créditos al diseño de las materias troncales de la titulación de Psicología. Revista de currículum y formación del profesorado, 14, pp. $237-250$.

Salgado, A. (2007). Investigación cualitativa: diseños, evaluación del rigor metodológico y retos. Liber 13, pp. 71-78.

San Martín, S., Jiménez, N., y Sánchez-Beato, E. (2016). La evaluación del alumnado universitario en el Espacio Europeo de Educación Superior. Aula Abierta,44(1), pp. 7-14. doi: https://doi.org/10.1016/j.aula.2015.03.003

Revista de Estudios Andaluces, núm. 36 (2018) pp.98-120. e-ISSN: 2340-2776 http://dx.doi.org/10.12795/rea.2018.i36.05 
Toledo Lara, G. (2018). El desarrollo de la reforma universitaria en España y el Espacio Europeo de Educación Superior. Barcelona, España: Bosch editor.

Tünnermann Bernheim, C. (2008). La autonomía universitaria en el contexto actual. Universidades, (36), pp. 19-46.

Vega Gil, L. (2017). El proceso de Bolonia y la escuela nueva. Un análisis comparado de convergencias y divergencias. Educação, Sociedade \& Culturas, 51, pp. 119-136.

Verger, A. (2013). Políticas de mercado, Estado y universidad: hacia una conceptualización y explicación del fenómeno de la mercantilización de la Educación Superior. Revista de educación, 360, pp. 268-291. doi: https://doi.org/10.4438/1988-592X-RE-2011-360-111 